\title{
ANTIDIABETIC ACTIVITY OF INDIAN MAHAGONI PLANT EXTRACT BY TRANSDERMAL THERAPY
}

\author{
STEPHAN $\mathbf{R}^{1}$, JEYABHARATHI $\mathbf{S}^{1 *}$, JEENATHUNISA ${ }^{2}$, DEENA PRISCILLA $\mathrm{H}^{2}$ \\ ${ }^{1}$ Department of Botany, Government Arts College, Ariyalur - 621 713, Tamil Nadu, India. ${ }^{1,2}$ Department of Microbiology, Cauvery College \\ for Women, Tiruchirappalli - 620 018, Tamil Nadu, India. Email: Jebiarkey2013@gmail.com
}

Received: 21 October 2017, Revised and Accepted: 19 December 2017

\section{ABSTRACT}

Objective: Most of the medicinal products are originated from nature and considered as a rich source for producing herbal drugs with modern approach. Swietenia mahagoni is one of the most important plants of the Meliaceae family. This plant has been reported to treat diabetes without adverse effects by local communities since long time. The present work is aimed on the transdermal therapy using seed extract of $S$. mahagoni in streptozotocin (STZ)-induced diabetes mellitus in male Wistar rats.

Methods: The induction of diabetic state by STZ injection and the biochemical analyses such as blood glucose, serum protein, albumin, cholesterol, urea, and alkaline phosphatase was monitored before and after treatment.

Results: This present study showed there was a significant $(\mathrm{p}<0.01)$ increase in the blood glucose level in diabetics, as well as, diabetics treated with insulin transdermally. However, there was significant reduction $(\mathrm{p}<0.05)$ in the hyperglycemic state in diabetic animal, which is transdermally treated with seed extract.

Conclusion: Thus, the results showed that this type of drug delivery could provide a pain-free physiological insulin balance among the patients.

Keywords: Modern drugs, Transdermal therapy, Swietenia mahagoni, Diabetes mellitus, Streptozotocin, Insulin.

(C) 2018 The Authors. Published by Innovare Academic Sciences Pvt Ltd. This is an open access article under the CC BY license (http://creativecommons. org/licenses/by/4. 0/) DOI: http://dx.doi.org/10.22159/ajpcr.2018.v11i4.23234

\section{INTRODUCTION}

The Swietenia mahagoni, also called "sky fruit" as the fruit, has upward trend toward the sky, consider as a beautiful, evergreen large tropical tree with a height of 30-40 m and girth of 3-4 $\mathrm{m}$ [1]. However, sometimes, the height of this long-lived deciduous tree with an umbrella-shaped crown reaches a height of up to $50 \mathrm{~m}$. S. mahagoni belongs to the Meliaceae family with 50 genera and 1400 species [2] phytochemical investigations supports this plant considered as high medicinal value plant [3]. It grows natively throughout the tropical regions of America, in particular, central and South American countries such as Mexico and Bolivia $[1,4,5]$ and in West Indies, Malaysia and Southern China [6]. The seeds of $S$. mahagoni have been reported to have anti-inflammatory, antimutagenicity, antioxidant [7], and antitumor activities [8]. An Bolivia Amazonian ethnic group has been used this seeds for leishmaniasis and as an abortion medicine. S. mahagoni seeds have been used as a folk medicine for treatment of diabetes, hypertension, and malaria [9]. The bark extract has been used as an astringent for healing wounds and occasionally for tanning because of the rich red color [10]. The hexane and methanol fractions of $S$. mahagoni extract exhibit lower efficacies of $23 \%$ and $60 \%$ inflammatory inhibition. The biologically active ingredients tetra- or tri-terpenoids and fatty acids are considered to be responsible for their therapeutic effects [11]. S. mahagoni seeds extract is high in lipids, particularly natural lipids glycolipids and phospholipids the most abundant of which is phosphatidylcholine [1214]. Polyphones are generally of the chemical patterns, phenolic groups react as hydrogen donors and neutralize the free radicals [13] hence consider for antidiabetic compound.

Diabetes mellitus is a major endocrine disorder affecting nearly $10 \%$ of total population. This condition occurs when the pancreas either no longer produces enough insulin or the cell stops responding to insulin. So that, glucose in blood cannot be absorbed into the cells of the body. Treatment includes changes in diet and, in some cases, the daily injection of insulin. So as to replace these therapeutic conditions, the transdermal drug delivery (TDD) has been greatly expanded through new technologies. The study of drug transport through the skin and other biomembrane has led to a significant advance in our ability to select drugs [15]. The delivery of drug into and through the skin was recognized to be an effective means of therapy for dermatologic regional and systemic disease [16]. An advantage associated with TDD includes avoidance of first past metabolism and variable absorbent including patient compliance. Some of the plants commonly used in the treatment of diabetes mellitus are Gymnema sylvestre, Murraya konige, Ocimum sanctum, Coccinia indica, Phyllanthus amarus [17], etc. S. mahagoni, a plant used in ayurvedic medicine, is useful in treating burning sensation, constipation, leprosy, worm infection bronchitis, inflammations, anemia, and diabetes (Source:www.celastineindia.com/ pankajoudhias).

The TDD has being greatly expanded through the application of new formulation technologies and active delivery system [16]. Now much wider set of drug compounds including macromolecules have the possibility to be delivered transdermally at therapeutic level. The use of TDD technology for any drug is clinically beneficial [18], and the transdermal delivery of vaccines has also been recently reported [19]. The non-invasive transdermal insulin delivery could provide diabetic patient with sustained physiological levels of basal insulin in a painfree manner. Hence, the researchers were interested to investigate the transdermal antidiabetic effect of $S$. mahagoni in streptozotocin (STZ)induced diabetes mellitus in rats.

\section{METHODS}

\section{Animals}

Adult male Wistar rats were purchased from Venkateshwara Enterprises, Bengaluru. These rats were housed in groups of 2-3 in separate cages and fed laboratory chow (Sri Durga seeds and foods, 
Bengaluru, India), water, and ad libitum. They were maintained in 12-h light and dark cycles to monitor their weight. All the experiments were carried out according to the guidelines of the committee for control and supervision of experiments on animals, New Delhi, India, and approved by the Institutional Animal Ethical Committee of Vinayaka Mission University (Approval No: IAECNo: Biotech/01/2008).

\section{STZ dosage preparation}

STZ (Fig. 1) (SRL, India) dissolved in citrate buffer of $\mathrm{pH} 4.5$ was given as single intradermal vein injection to the rats under minimal diethyl ether anesthesia. The dosage of STZ was $50 \mathrm{mg} / \mathrm{kg}$ body weight. The control rats were given citrate buffer injections.

\section{Preparation of seed extract}

About $30 \mathrm{~g}$ of $S$. mahagoni powdered seed was taken and mixed with $100 \mathrm{ml}$ benzene kept in Soxhlet extraction apparatus overnight to collect the seed extract (Fig. 2).

\section{Transdermal drug therapy}

Groups A and B did not receive any treatment. The experimental rats were maintained for about a period of 16 days with periodically monitoring of body weight and blood glucose concentrations. Diabetic rats were taken for the transdermal drug therapy. The band-aid contained seed extract $(0.05 \mathrm{ml})$ was stuck on the abdominal region of Group C rats. Agarose and Aloe vera leaf gel with seed extract $(0.05$ $\mathrm{ml}$ ) was pasted on the abdominal region of Groups D and E rats using plaster, respectively.

\section{Biochemical test}

Blood is collected from the tail of Wistar rats by tail snipping method for the biochemical analysis (Table 1).

\section{Statistical analysis}

The result obtained in the present investigation was subjected to statistical analysis such as standard deviation (SD) and Student's t-test.

The SD was calculated by the following formula

$$
\text { Standard deviation }(\mathrm{SD})=\sqrt{\sum \frac{(X-X)^{2}}{n-1}}
$$

Where, "X" refers to one variable, $\mathrm{X}$ refers to mean of the variable, and $\mathrm{n}$ refers to the total number of samples.

Student's $t$-test was used to compare difference between the mean value of control and experimental groups. It was calculated using the formula,

$$
\begin{gathered}
/ \mathrm{t} /=\frac{X 1-X 2}{S} \sqrt{\frac{n_{1} n_{2}}{n_{1}+n_{2}}} \\
\text { Where } S=\frac{\sqrt{\sum\left(x_{1}-x_{1}\right)^{2}+\sum\left(x_{2}-x_{2}\right)^{2}}}{\left(\mathrm{n}_{1}+\mathrm{n}_{2}\right)-2}
\end{gathered}
$$

Where, $X_{1}$ and $X_{2}$ are the mean value of two variables. The levels of significance for the " $\mathrm{t}$ " values at corresponding degree of freedom $=\left(n_{1}+n_{2}\right)-2$. Where, " $n_{1}$ " and " $n_{2}$ " are the number of samples in two variables.

\section{RESULT AND DISCUSSION}

The injection of STZ destroys the beta cells of pancreas, besides producing the other toxic effects in liver, kidneys, etc. Thus, the Type- 1 diabetes produces the acute metabolic complications such as diabetic ketoacidosis and hyperosmolar non-ketotic. The acute deficiency of insulin causes absolute increase in glucagons concentration. The stock

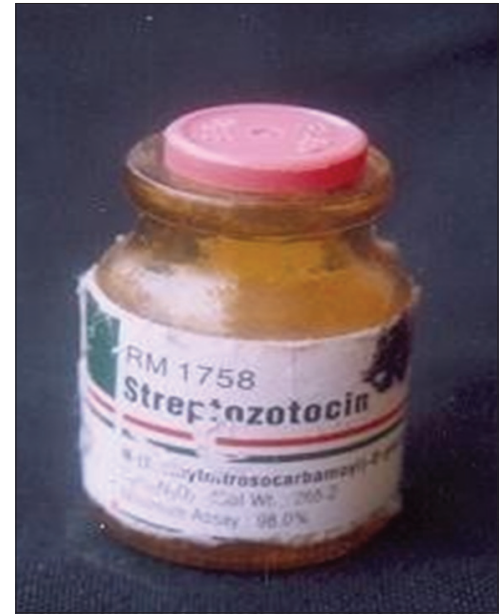

Fig. 1: Streptozotocin (SRL, India)

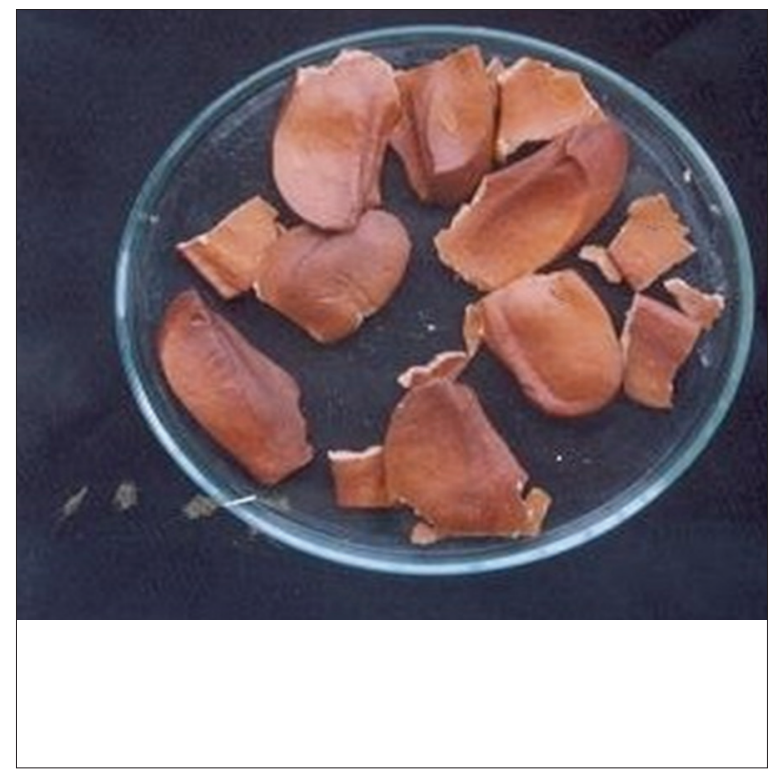

Fig. 2: Swietenia mahagoni seed

produced by STZ could enhance cortical hormones and catecholamine [20]. The catecholamine presumably blocks the release of small amounts of insulin from the residual undamaged beta cells and inhibits the insulin-induced transport of glucose into the peripheral tissues. These hormonal changes have two critical effects such as induce maximal glucogenesis and impair peripheral utilization of glucose causing severe hyperglycemia. Furthermore, glucagons facilitate gluconeogenesis inducing a fall in fructose-2, 6-bisphosphate the intermediate that stimulates glycolysis and blocks gluconeogenesis. The fructose-2, 6-bisphosphate level falls the process of glycolysis and gluconeogenesis were inhibited or later on enhanced. The hyperglycemia induces osmotic diuresis that leads to extracellular volume depletion and dehydration that characterize the ketoacidosis state to develop the metabolic acidosis

For ketosis to occur changes must be produced both in adipose tissue and liver. Free fatty acids (FFAs) mobilized from adipose tissue are the primary substrates for ketone body formation and plasma levels of FFAs would raise FFA which was taken by the liver to re-esterify into triacylglycerol and converted to very low-density lipoprotein (VLDL) and transported back into circulation. In diabetic condition, the insulin deficiency, fatty acid oxidation in the liver is enhanced, which is induced 
by glucagon. Glucagon accelerates the carnitine palmitoyltransferase system of enzymes responsible for transport of fatty acids into the mitochondria for oxidation. Ketosis is a first-order function of fatty acids reaching carnitine palmitoyltransferase 1 .

The rise in cyclic adenosine monophosphate levels activate the $2 \mathrm{C}$ protein kinase- and consequently phosphorylate, the triacylglycerol lipase adipose tissues, undergo hydrolysis to release glycerol and three fatty acids into the blood plasma. These FFAs are taken by the liver. Some FFAs are oxidized and some are resynthesized into triacylglycerol, which are released into blood as VLDL. Thus, in STZ diabetes release of VLDL by liver into blood was increased [21]. Lipoprotein lipase is inhibited by glucagon and catecholamines which elevate the plasma levels of triacylglycerol and cholesterol in blood, not because of their biosynthesis is higher, but they are not metabolized at normal rates.

In this present study, there was a very significant $(\mathrm{p}<0.01)$ increase in the blood glucose level in diabetics as well as diabetics treated with insulin transdermally. However, there was significant reduction $(p<0.05)$ in the hyperglycemic state in diabetic animal, which was transdermally treated with seed extract. The injection of STZ destroys the beta cells of pancreas, besides producing the other toxic effects in liver, kidneys, etc. Thus, the Type- 1 diabetes which produces the acute metabolic complications such as diabetic ketoacidosis and hyperosmolar nonketotic leads to absolute increase in glucagon concentration. The stock produced by STZ could enhance cortical hormones and catecholamines [20]. The catecholamine presumably blocks the release of small amounts of insulin from the residual undamaged beta cells and inhibits the insulin-induced transport of glucose into the peripheral tissues. After the transdermal seed extract treatment, there was a significance reduction in the alkaline phosphatase, cholesterol, and blood urea to the normal rat group increase in the protein and albumin. It shows that the extract may regenerate pancreatic isolate in STZ-induced diabetic rat, and thereby reduce the diabetics. In Group $\mathrm{C}$ diabetic rats, the body weight and general health are maintained normally due to the transdermal treatment of seed extract in band aid. Transdermal S. mahagoni treatment was confirmed by biochemical tests. STZinduced animals received the treatment, showed rapid normalization of blood glucose level in comparison of control (Tables 2 and 3).

The TDD system (TDDS) has potential advantages of avoiding hepatic first-pass metabolism, maintaining constant blood levels for longer period of time decrease the side effects, decrease gastrointestinal effect that occur due to local contact with gastric mucosa and improved compliance [22]. The release pattern form TDDS is studied by in vitro (ex vivo) models using artificial membranes or animal or cadaveric skin. The hairless guinea pigs and Brattleboro rat appear to be good models for investigating TDDS. Ethyl cellulose polyvinylpyrrolidone film contains diltiazem hydrochloride and indomethacin. The influences of initial drug concentration, film composition, and film thickness on the in vitro drug release rate as well as drug permeation through rat abdominal skin were studied using paddle over skin method [4,5]. Chitosan membrane with different permeability to propranolol hydrochloride was obtained by controlled cross-linking with glutaraldehyde to regulate the drug release in the devices. Chitosan gel was used as the drug reservoir. The ability of these devices to deliver the drug while supported on rabbit pinna skin was tested by conducting in vitro studies [8].

Carboxymethyl cellulose sodium-based TDD for propranolol was used to evaluate the in vitro and in vivo performance. In vitro studies using excised hair free rat. Skin model in a modified Franz diffusion cell resulted in $66.54 \%$ permeation at the end of $24 \mathrm{~h}$ in a zero-order permeation profile [8].

From the above reviews and experimental results, it was concluded that the transdermal delivery of $S$. mahagoni seed extract helps to prevent the diabetic complications and serve as a good adjuvant in the present armamentarium of antidiabetic drug delivery method.

\section{CONCLUSION}

The present study clearly indicated the significance antidiabetic activity with the transdermal delivery of S. mahagoni seed extract in band aid method. It showed that the extract may regenerate pancreatic isolate in STZ-induced diabetic rat, and thereby reduce the diabetics. In Group $\mathrm{C}$ diabetic rats, the body weight and general health are maintained normally due to the transdermal treatment of seed extract in band aid. Transdermal $S$. mahagoni treatment was confirmed by biochemical tests. STZ-induced animals received the treatment, showed rapid normalization of blood glucose level in comparison to control. Hence, it is concluded that the transdermal delivery of $S$. mahagoni seed extract helps to prevent the diabetic complications and serve as a good adjuvant in the present armamentarium of antidiabetic drug delivery method.

The future for TDD hinges on how it is perceived by companies involved in drug discovery. In the past, it has been used as an alternative to oral delivery to overcome problems associated with that route. If transdermal delivery continues to be viewed in this context, then, future advances are likely be incremental, as the drugs will not have been

Table 1: Biochemical analysis

\begin{tabular}{|c|c|c|c|}
\hline S. no & Analysis & Method & Calculations \\
\hline 1 & Blood glucose & $\begin{array}{l}\text { Glucose estimation } \\
\text { kit (AGAPPIE) }\end{array}$ & Blood glucose $(\mathrm{mg} \%)=\frac{\text { Absorbance of test }}{\text { Absorbance of Standard }} \times 200 \mathrm{mg} / \mathrm{dl}$ \\
\hline 2 & Serum protein & Biuret & Total proteins $(\mathrm{mg} \%)=\frac{\text { O.D of }(\text { Test })}{\text { O.D of }(\text { Standard })} \times 6$ \\
\hline 3 & Serum albumin & BCG dye binding & Albumin $(\mathrm{mg} \%)=\frac{\text { O.D of }(\text { Test })}{\text { O.D of }(\text { Standard })} \times 4$ \\
\hline 4 & Serum cholesterol & $\begin{array}{l}\text { Enzymatic (cholesterol } \\
\text { oxidase-peroxidase) }\end{array}$ & Cholesterol concentration $(\mathrm{mg} / \mathrm{dl})=\frac{\text { O.D of Test }}{\text { O.D of Standard }} \times 30$ \\
\hline 5 & Serum urea & DAM & $\begin{array}{l}\text { Serum/plasma: } \\
\text { urea in } \mathrm{mg} / 100 \mathrm{ml}=\frac{\text { Absorbance of test }}{\text { Absorbance of Standard }} \times 200\end{array}$ \\
\hline 6 & Alkaline phosphatase & Kind and King's & Serum alkaline phosphates Activity in KA units $=\frac{\text { O.D Test }- \text { OD Control }}{\text { O.D Standard }- \text { OD Blank }} \times 10$ \\
\hline
\end{tabular}


Table 2: Variations in blood glucose of male Wistar rats $(\mathrm{mg} / \mathrm{dl})$

\begin{tabular}{llllll}
\hline Days & Control & Diabetic & $\begin{array}{l}\text { Diabetic+band aid+seed } \\
\text { extract }\end{array}$ & $\begin{array}{l}\text { Diabetic+aloe vera gel+seed } \\
\text { extract }\end{array}$ & $\begin{array}{l}\text { Diabetic+agarose gel+seed } \\
\text { extract }\end{array}$ \\
\hline Day 0 & $77 \pm 12.674$ & $77 \pm 12.674$ & $77 \pm 12.674$ & $77 \pm 12.674$ & $77 \pm 12.674$ \\
Day 3 & $76 \pm 7.69$ & $239 \pm 7.60$ & $305 \pm 7.60$ & $280 \pm 6.40$ & $320 \pm 4.67$ \\
Day 16 & $89 \pm 14.03$ & $390 \pm 11.08$ & $361 \pm 11.15$ & $398 \pm 3.01$ & $410 \pm 10.30$ \\
\hline
\end{tabular}

The values are \pm mean values

Table 3:Variations in blood serum of male Wistar rats

\begin{tabular}{lllll}
\hline Observed effects & Control & Diabetic & $\begin{array}{l}\text { Diabetic+band } \\
\text { aid+seed extract }\end{array}$ & $\begin{array}{l}\text { Diabetic+aloe vera } \\
\text { gel+seed extract }\end{array}$ \\
\hline Serum total protein $(\mathrm{mg} / \mathrm{dl})$ & $6.95 \pm 0.450$ & $6.28 \pm 0.895$ & $7.42 \pm 0.493$ & $6.26 \pm 0.764$ \\
Sel+seed extract & $3.86 \pm 0.59$ & $2.85 \pm 0.15$ & $4.81 \pm 0.86$ & $2.73 \pm 0.230$ \\
Serum albumin $(\mathrm{mg} / \mathrm{dl})$ & $132.8 \pm 11.29$ & $176 \pm 13.3$ & $128 \pm 12.48$ & $174 \pm 14.28$ \\
Berum total cholesterol (mg/dl) & $43.33 \pm 11.26$ & $56.66 \pm 4.88$ & $28.24 \pm 8.89$ & $56.78 \pm 3.33$ \\
Alkaline phosphatase (IU/L) & $4.2 \pm 1.743$ & $30.78 \pm 4.30$ & $9.03 \pm 2.58$ & $28.68 \pm 6.52$ \\
\hline
\end{tabular}

The values are \pm mean values

selected with a view to their suitability for transdermal delivery. The emphasis of developments will be in overcoming problems associated with the barrier properties of the skin the approaches being taken to overcome these problems.

Another factor that might be important for the future direction of transdermal delivery is the current surge in interest in nanotechnology. Application of developments could lead to systems where a single device could monitor drug levels by sampling through the skin and thus provide controlled delivery of drugs.

\section{REFERENCES}

1. Rastogi RP, Mehotra BN. Compendium of Indian Medicinal Plants. Vol. 1. New Delhi: CSIR Publication; 1990. p. 1960-9.

2. Arumugasamy K, Latha KV, Kumar NH. Studies on some pharmacognostic profiles of Swietenia macrophylla. King. Anc Sci Life 2004;24:97-102.

3. Madhumitha S, Vinothkumar D, Babu NG. Phytochemical analysis and antibacterial activity of Swietenia mahagoni: A highly medicinal plant in India. Asian J Pharm Sci Clin Res 2016;9:62-4.

4. Rao MY, Vani G, Chary BR. Design and evaluation of muco adhesive drug delivery systems. Indian Drugs 1998;35:558-65.

5. Rao PR, Diwan PV. Formulation and in vitro evolution of polymeric films of diltiazen hydrochloride and indomethacin for transdermal administration. Drug Dev Indian Pharm 1998;24: 327-36.

6. Andrew J Thompson, Alison C Jackson, Rachael C Symonds, Barry J Mulholland, A Ruth Dadswell, Patrick S Blake, Alan Burbidge, Ian B Taylor. Ectopic expression of a tomato 9-cis-epoxycarotenoid dioxygenase gene causes over-production of abscisic acid. Plant J 2000;23:363-74

7. Hajra S, Mehta A, Pandey P. Phenolic compounds and antioxidant activity of Swietenia mahagoni seeds. Int J Pharm Pharm Sci 2011:3:431-4

8. Thacharodi D, Rao KP. Rate - Controlling bio molecular membranes as transdermal delivery systems for nifedipine: Development and in vitro evaluations. Biomaterials 1996;17;1307-11.

9. Kadota S, Marpaung L, Kikuchi T, Ekimoto H. Constituents of the seed of Swietenia mahagoni JACQ. I. Isolations, structures and $1 \mathrm{H}$ and $13 \mathrm{C}$ nuclear magnetic resonance signal assignment of new tetranortriterpenoids related to Swietenine and Swietenolide. Chem Pharm Bull 1990;38:639-51.

10. Falah S, Suzuki T, Katayama T. Chemical Constituents from Swietenia macrophylla bark and their antioxidant activity. Pak J Biol Sci 2008;16:2007-12.

11. Bacsal K, Chavez L, Diaz I, Espina S, Javillo J, Manzanilla H, et al. The effect of Swietenia mahogani (Mahogany) seed extract on indomethacin-induced gastric ulcers in female Sprague-Dawley rats. Acta Med Philipp 1997;33:127-39.

12. Krishna R, Pandit JK. Carboxymethylcellulose-sodium based transdermal drug delivery system for propranolol. J Pharm Pharmacol 1996;48:367-70.

13. Kulisic T, Radonic A, Katalinic V, Milos M. Use of different methods for antioxidative activity of oregano essential oil. Food Chem 2004;85:633-40

14. Majid MA, Rahman IM, Shipar MA, Helal UM, Chowdhury R. Physico-chemical characterization. Antimicrobial activity and toxicity analysis of Swietenia mahagoni oil. Int J Agric Biol 2004;6:350-4.

15. Potts RO, Cleary GW. Transdermal drug delivery: Useful paradigms. J Drug Target 1995;3:247-51.

16. Kalia YN, Merino V, Guy RH. Transdermal drug delivery. Clin Aspects 1990;1:361-8.

17. Adedapo AA, Ofuegbe SO, Adeyemi AA. The anti-diabetic activities of the methanol leaf extract of Phyllanthus amarus in some laboratory animals. Asian J Med Sci 2013;4:23-34.

18. Naik A, Kalia YN, Guy RH. Transdermal drug delivery: Overcoming the skin's barrier function. Pharm Sci Technolo Today 2000;3:318-26.

19. Glenn GM, Dietrich G, Werner G. Transcutaneous Immunization in Vaccine Delivery Strategies. Norfolk UK: Horizon Scientific Press; 2002. p. $53-81$

20. Hampenstall PD, Campbell JP, Bajurnow T, Reed PC, Harrison LC. Cardiovascular, bio chemical and hormonal response to intravenous sedation with local analgeica versus general anesthesia in patients undergoing oral surgery. J Oral Maxillofaec Surg 1986;44:441-6.

21. Naveen YP, Urooj A. Amelioration of diabetes by Swietenia mahagoni in streptozotocin induced diabetic rats. Int J Pharm Sci Res 2015;6:3892.

22. Panchagula R. Transdermal delivery of zidovudine: Effect of vehicles on permeation across rat skin and their mechanism of action: Pharmacol Res 1997;47:140-56. 